\title{
LA CIENCIA POLÍTICA EN COLOMBIA: UNA DISCIPLINA EN CONTINUA EXPANSIÓN*
}

\author{
Political Science in Colombia: A Discipline in Constant Growth
}

\section{SANTIAGO LEYVA}

Universidad EAFIT

\section{MARÍA FERNANDA RAMÍREZ}

\author{
Universidad EAFIT
}

\begin{abstract}
RESUMEN
En la última década la disciplina avanzó vertiginosamente en su consolidación como profesión, en la construcción de comunidad académica y en su capacidad para producir conocimiento acumulable. Se destaca la continuidad en la expansión de los programas académicos, la creación de la Asociación Colombiana de Ciencia Política, la celebración de tres congresos y dos encuentros disciplinares, el crecimiento en el número de egresados y el posicionamiento de dos de las revistas en ISI/Scopus. No obstante, este proceso de expansión también ha creado retos en cuanto al sostenimiento de la calidad de la docencia y la ampliación de los espacios laborales. Igualmente, el conocimiento generado es principalmente descriptivo, cualitativo, monográfico y no comparado, lo que muestra que es necesario seguir diversificando las habilidades metodológicas.
\end{abstract}

Palabras clave: Ciencia política, Colombia, disciplina, institucionalización, educación.

\begin{abstract}
In the last decade the discipline continued its consolidation as a new profession, its construction of an academic community and its ability to produce accumulative knowledge. Some highlights of these 10 years were the continued expansion of programs (at undergraduate and graduate levels), the creation of the Colombian Association of Political Science, the completion of three congresses and two disciplinary meetings, the expansion in the number of graduates and the acceptance of two Colombian journals to both ISI and Scopus. However, this expansion has also created challenges for the maintenance of the quality of teaching and expansion of new labor spaces. It is also important to further strengthen the methodological skills, given that the knowledge generated is eminently descriptive, qualitative, and not compared.
\end{abstract}

Key words: Political Science, Colombia, discipline, institutionalization, education.

* Este artículo deriva de la investigación La Ciencia Política en Colombia. Una mirada a sus orígenes y fundadores, en el marco del grupo "Sociedad, Política e Historias Conectadas" del Departamento de Gobierno y Ciencias Políticas de la Universidad EAFIT, la que ha contado con financiación de Colciencias y de la Universidad EAFIT.

Los autores agradecen la invaluable colaboración, responsabilidad y compromiso de un equipo de estudiantes de la Universidad EAFIT, integrado por el practicante Juan David Correa y el monitor académico Santiago Quintero, junto con Andrés Olaya, Juliana Rodríguez, Laura Toro y Alejandro Muñoz. 


\section{INTRODUCCIÓN}

El presente trabajo pretende dar cuenta del estado de la Ciencia Política en Colombia. A tal fin se concentra en una exploración de la trayectoria experimentada por los programas existentes en el país, basada en información proveniente del Ministerio de Educación Nacional, así como de entrevistas realizadas a algunos de los fundadores de la disciplina. ${ }^{1}$ Por otra parte, realiza un diagnóstico empírico de la Ciencia Política que se publica en el país, a partir de los resultados de una base de datos que reúne información de las cuatro revistas académicas de mayor prestigio y de las principales editoriales que publican libros de Ciencia Política entre 2005 y 2014; incluyéndose en total 730 artículos de revista y 239 libros.

Cabe señalar que este texto busca dar continuidad al reconocido artículo de Bejarano y Wills (2005) sobre la Ciencia Política en Colombia, el cual, hasta el día de hoy es un referente ineludible para quienes están interesados en estudiar y conocer su historia. En ese trabajo, las autoras describen la evolución de la disciplina en el país desde sus inicios (1968-1986), pasando por el momento del desarrollo de las publicaciones y de la investigación (1982-1990), hasta la etapa de expansión y diversificación de programas académicos (1990-2005). En el marco de esa periodización, Bejarano y Wills muestran como "la ciencia política en Colombia no solo se abrió paso, sino que ganó autonomía y prestigio en el campo académico", lo que explican "por el deslindamiento de las pasiones partidistas y de las polarizaciones intelectuales, así como la utilización de estrategias para sobrevivir el embate de la guerra" (2005: 111). No obstante, alertan sobre la necesidad de fortalecer la comunidad nacional de politólogos creando instancias de autorregulación y un encuentro anual en el que se generen oportunidades para el debate y la profundización teórica. También señalan la necesidad de lograr una vinculación más efectiva con la comunidad académica internacional, entre otros factores requeridos para la institucionalización disciplinar.

Por otra parte, es importante aclarar que se tomaron en cuenta los numerosos estudios que en los últimos años se han preocupado, con diversos grados de sistematicidad y soporte empírico, por hacer un estado del arte de la disciplina en el país. Estos muestran perspectivas encontradas respecto de la notable expansión experimentada por la Ciencia Política en Colombia. Así, por un lado, están aquellos que celebran el crecimiento de la disciplina tras un largo y trabajoso proceso, entre otros, Leal (2011); Sánchez (2011); Cuéllar (2007); Barrero y Angel (2014). Por el otro, están quienes desde una visión más escéptica, alertan sobre los riesgos de una expansión desmesurada como Murillo y Ungar (1999); Alonso (2001), Losada (2004) y Restrepo et al. (2008), entre otros. Sin pretender zanjar esta contienda, con este artículo se busca evidenciar los avances más importantes

1 Dentro del ciclo: “Conversaciones con los pioneros de la Ciencia Política en Colombia”, organizado por el Departamento de Gobierno y Ciencias Políticas a partir de 2014 y vigente en la actualidad, los autores entrevistaron a los reconocidos académicos Rodrigo Losada, Fernando Cepeda, Francisco Leal, Fernán González y Daniel Pécaut, quienes como protagonistas de la fundación y desarrollo de la Ciencia Política en el país, aportaron su visión y balance de dichos procesos. 
en el proceso de institucionalización de esta disciplina, al tiempo que se ilustran los retos más importantes que aún persisten para su fortalecimiento.

El texto está organizado de la siguiente manera. En primer lugar, se hace referencia a la expansión de los programas de formación en Ciencia Política en el país. Luego se presenta el proceso de construcción de comunidad, con sus progresos y retos. En tercer término se muestra la regionalización de la disciplina, con sus asimetrías y desafíos. Posteriormente se examinan los avances en cuanto a la profesión y la creciente inserción laboral del politólogo. Finalmente, se consideran los resultados de la revisión empírica del conocimiento producido en la disciplina entre 2005 y 2014. Por último, se presentan las conclusiones.

\section{LA "EXPLOSIÓN PROLONGADA" DE LA FORMACIÓN EN CIENCIA POLÍTICA}

Bejarano y Wills (2005) llamaban la atención sobre la "explosión" de los programas de pregrado que se había dado en los previos diez años. En Colombia, el primer programa de pregrado en Administración Pública comenzó en 1962 en la Escuela Superior de Administración Pública, en Ciencia Política en 1968 en la Universidad de los Andes y el de maestría en Estudios Políticos en 1972 en la Universidad Javeriana, pero de esos años hasta 1989 solo se crearon dos programas más, alcanzando un total de cinco programas en 1989, todos ellos localizados en tres universidades de Bogotá y bajo enfoques epistemológicos muy distintos. En los diez años siguientes se crearon 14 nuevos programas, es decir, en 1999 existían 19 programas en total (9 de pregrado y 10 de posgrado, 9 de ellos de maestría) (Duque, 2013). Luego, para 2005, existían 53 programas, 16 de pregrado y 37 de pregrado.

En 2015, según datos del Sistema Nacional de Información de la Educación Superior (SNIES), en Colombia hay 99 programas de Ciencia Política, ${ }^{2} 64$ de posgrado (incluyendo 3 de doctorado, 25 de maestría y 36 de especialización) y 35 de pregrado. Como se puede ver en el Gráfico 1, solo entre 2009 y 2013 se crean el 30\% de los programas que hoy existen en el país, sin duda un reto enorme para ofrecer una formación de calidad, pero también un hecho que hace evidente que la Ciencia Política se posicionó como el área más dinámica de las ciencias sociales en Colombia.

Más sorprendente es constatar cómo se duplican los programas de formación posgradual en Ciencia Política, tomando algo de distancia de los programas generalistas en "estudios políticos". A nivel de posgrados es importante resaltar el surgimiento de los programas de gobierno, dirigidos a la formación de los funcionarios públicos. Cabe aquí decir que la educación en Administración Pública nunca despegó realmente en el país, pues por

2 El SNIES arroja 167 programas, pero se los separó por áreas, obteniendo 99 de Ciencia Política y afines, 34 de Relaciones Internacionales (importante aclarar que estos no mencionan en su nombre a la primera), 19 de resolución pacífica o negociada de conflictos (incluyendo programas tecnológicos en formación ciudadana) y 15 más que corresponden a otras áreas. 
Gráfico 1. Ascenso de la formación en Ciencia Política desde 1998

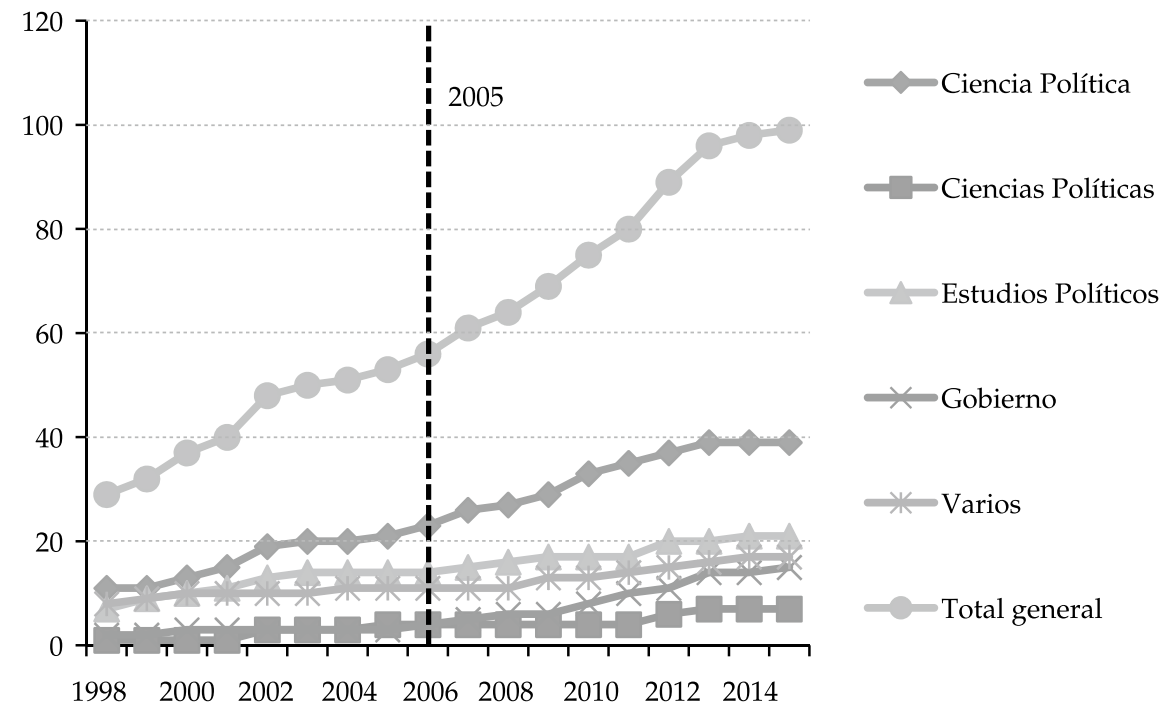

Fuente: Elaboración propia con datos del SNIES 2015, datos disponibles desde 1998.

Tabla 1. Denominación y nivel de formación de los programas de Ciencia Política y afines

Denominación

Tipo de formación

Ph.D. Maestría Especialización Universitaria Tecnológica Total general

\begin{tabular}{lcccccc}
\hline Ciencia Política & 1 & 4 & 13 & 21 & 0 & 39 \\
Ciencias Políticas & 0 & 1 & 0 & 6 & 0 & 7 \\
Estudios Políticos & 2 & 13 & 5 & 1 & 0 & 21 \\
Gobierno & 0 & 6 & 5 & 3 & 1 & 15 \\
Varios & 0 & 1 & 13 & 1 & 2 & 17 \\
Total general & 3 & 25 & 36 & 32 & 3 & 99 \\
\hline
\end{tabular}

Fuente: elaboración propia con datos del SNIES 2015.

diversas razones históricas, solo existen unos pocos pregrados y un par de maestrías en este tema. ${ }^{3}$ Esto implica que el gran espacio de formación del funcionariado nacional y

3 A pesar del inicio temprano de la formación en Administración Pública (1962), la Escuela Superior de Administración Pública (de naturaleza pública e inspirada por la experiencia francesa) no logró tener el mismo impacto, ni desarrollar una planta de profesores con tanta influencia como ocurrió con la de los pioneros en Ciencia Política en la Universidad de los Andes, en parte por la vulnerabilidad a la "clientelización" de la primera. Para el caso de la formación en Administración Pública tampoco se dio la explosión de nuevos pregrados en los años noventa, quizás porque la liberalización de la educación superior coincidió con el desprestigio de las burocracias en el marco de las reformas neoliberales. Lo anterior llevó a que los estudios de Ciencia Política y los de Administración Pública tengan aún hoy una gran distancia en calidad y cantidad, 
regional se está abriendo como un nicho clave para el futuro del área y que este proceso se está dando, en la mayoría de los casos, dentro de los departamentos de Ciencia Política.

Como ya se ha mencionado, el crecimiento no ha sido recibido con beneplácito por todos. Algunos han alertado sobre los riesgos que esta "explosión" puede traer, entre otros, Losada (2004: 13) señala que la Ciencia Política "se está usando a la ligera", debido a la ausencia de doctores que "puedan sustentar con seriedad los numerosos programas que alegan enseñar Ciencia Política". Otros, con una mirada descentralizada, valoran la "explosión" señalando que esta puede servir para producir conocimiento sobre la política colombiana (Cuéllar, 2007: 282); o para propiciar un proceso de institucionalización que comenzó por la profesionalización y la creación de una comunidad, antes que por la creación de una disciplina (Leyva, 2013). Finalmente, también hay visiones positivas, Duque (2013: 95) por ejemplo, señala que "una mirada de conjunto permite apreciar los avances de la disciplina", incluyendo progresos importantes en el nivel educativo de los docentes, nuevas publicaciones que se han consolidado y la creación de una asociación de politólogos.

Otro punto sobre el que hay discusión es el estado actual de la disciplinariedad. Algunos trabajos han encontrado un "retorno a la disciplinariedad" (Restrepo et al., 2008: 89), mientras que otros consideran que la mayoría de los pregrados invocan "a la inter, multi o transdisciplinariedad y al diálogo de saberes", mostrando currículos que reflejan programas más generales de ciencias sociales, derecho y política, o de filosofía política (Fortou et al., 2013:176). Para aportar datos a este debate, Fortou y Leyva (2013) exploraron la bibliografía citada en los microcurrículos de algunas materias de los programas afiliados a la ACCPOL, para identificar a qué autores leían los estudiantes de pregrado de Ciencia Política. En general, se encontró una alta presencia del pensamiento europeo continental y una baja citación a autores de Ciencia Política norteamericana. No obstante, también se constató en ese trabajo una tendencia incipiente a leer algunos de los estudios y autores que pueden ser considerados como pioneros de la disciplina (Fernán González, Francisco Leal, María Teresa Uribe, Rodrigo Losada, entre otros) y a incluir textos colombianos en la bibliografía básica de introducción a la disciplina, como el manual de "Enfoques para el Análisis Político" de Losada y Casas (Losada y Casas, 2008). Las citas comunes y la preocupación por los enfoques sugieren que se están empezando a forjar unos referentes comunes para la disciplina en el país, a pesar de que se sigue leyendo más a los autores foráneos y a los de otras disciplinas.

En general, el crecimiento continuado hace difícil comparar y generalizar los programas, algunos cuentan ya con casi 50 años de historia, otros fueron formados uno o dos años atrás. La distancia es amplia y los espacios de trabajo conjunto no son muchos, aun cuando existen puntos de contacto como los congresos y las revistas. Igualmente, a nivel nacional no existe realmente ningún sistema de regulación que haga recordar al esfuerzo que se hizo en la Unión Europea por homologar (aunque dejando espacio para la flexibilidad) 
a casi 600 pregrados de la disciplina. ${ }^{4}$ Esto permite señalar respecto de la docencia que, como tantas otras cosas en Colombia, la Ciencia Política también es desigual.

\section{UNA COMUNIDAD DISCIPLINAR EN CONSTRUCCIÓN}

Hace diez años Bejarano y Wills (2005: 21) planteaban que en Colombia aún no existía realmente una "comunidad intelectual" en la Ciencia Política, solo "pequeñas islas" sin mucha interconexión. Entonces, según las autoras, no se contaba con un congreso disciplinar y por lo tanto se carecía de "una cultura de debate crítico, oral y escrito". Además, mencionaban en su texto que estas "islas" se ubicaban en seis ciudades de Colombia, pero que debido al surgimiento rápido y poco orgánico de los nuevos programas, respecto de la ruta trazada desde finales de los años sesenta en Bogotá, la disciplina se expandía de manera muy fragmentada.

Un parteaguas de esta situación fue la fundación en 2008 de la Asociación Colombiana de Ciencia Política (ACCPOL) por doce universidades. La Asociación hoy cuenta con 23 miembros, es decir, casi las dos terceras partes de las universidades con pregrado en Ciencia Política (Muñoz, 2013). ${ }^{5}$ Desde entonces la ACCPOL ha organizado tres congresos: el primero en 2008 en Bogotá en la Universidad de los Andes; el segundo en 2010 en Barranquilla en la Universidad del Norte y el más reciente en 2014 en Cali, en las universidades Javeriana e ICESI, con una sede alterna en la ciudad de Popayán en la Universidad del Cauca.

Este surgimiento de la ACCPOL no ha sido sin contratiempos: la asociación tuvo algunos problemas administrativos en 2011 y debió postergar su congreso desde 2012 hasta 2014, pero se logró reorganizar cuando asumió la presidencia la profesora Patricia Muñoz, de la Universidad Javeriana. Esta pequeña crisis sirvió para generar el 1er. Encuentro de Facultades y Programas de Ciencia Política, en Medellín, en las universidades EAFIT y Pontificia Bolivariana, evento que dio lugar a un libro sobre la institucionalización de la Ciencia Política en Colombia (Leyva, 2013). Dos años más tarde se organizó una nueva versión de este encuentro en la ciudad de Ibagué, en las universidades del Tolima y de Ibagué. ${ }^{6}$ En resumen, se han realizado cinco eventos desde la fundación de la asociación

4 En Colombia existe un sistema de homologación de alta calidad, pero según datos del SNIES solo siete de los pregrados del país aparecen homologados como de alta calidad. Se trata entonces de una homologación voluntaria y que no fija parámetros “deseables" o una línea mínima. En este sentido, la Ciencia Política contrasta profundamente por su falta de regulación y ausencia de estándares con otras disciplinas altamente reglamentadas como la Psicología, la Medicina y el Derecho. Adicionalmente, existe en Colombia un registro calificado que es obligatorio para todos los programas, pero que no implica realmente un ejercicio de revisión profunda por parte del Ministerio de Educación Nacional.

5 Una de sus particularidades es que sigue siendo una asociación en la que solo es permitida la afiliación institucional, por lo que se sostiene con las cuotas anuales pagadas por las universidades más los fondos que resultan de la organización de los congresos. Sus recursos le alcanzan para pagar un director ejecutivo de tiempo parcial desde 2013 y para mantener un sitio web activo.

6 Los encuentros se diferencian de los congresos porque buscan concentrar la reflexión sobre un solo tema de carácter más disciplinar que temático, explorando aspectos de la formación de pregrado, la investigación en Ciencia Política, la inserción profesional de los egresados, etc. Este tipo de enfoque fue inspirado por el Teaching and Learning Conference que organiza todos los febreros la Asociación Americana de Ciencia Política. 
en 2008 y dos más están programados para 2015 y 2016. Como muestra la tabla 2, solo teniendo en cuenta los tres congresos se han presentado 906 ponencias y han asistido a estos espacios más de 2500 personas; el último congreso en Cali tuvo una asistencia de más de 1200 personas y 460 ponentes, cifras que muestran el creciente interés que suscita la disciplina.

En cuanto a los temas que se discuten en los congresos, se puede ver en la tabla 2 que destaca la presencia de áreas como el conflicto armado colombiano, las políticas públicas, las relaciones internacionales y los sistemas electorales y movimientos sociales. Llama la atención, por otra parte, la poca presencia de discusiones metodológicas y trabajos comparativos, similar a lo encontrado en la exploración de publicaciones, como se verá más adelante. Para dar cuenta de la agenda de la disciplina en estos eventos también resulta útil recordar que los invitados internacionales a estos tres congresos fueron: al primero, Manuel Alcántara (España), Evelina Dagnino (Brasil), Rut Diamint (Argentina), Edward Gibson (EE.UU.); al segundo, Michael Coppedge (EE.UU.); y al tercero, Stathis Kalyvas (Grecia), Richard Snyder (EE.UU.), Frank Pfetsch (Alemania) y David Altman (Uruguay-Chile). Se constata, por lo tanto, una mayoría de invitados de Estados Unidos, seguido por profesores del cono sur.

Resulta claro, entonces, que los progresos en la construcción de una comunidad académica son notables. Sin embargo, los avances de estos diez años no pueden ocultar que los retos siguen siendo grandes, especialmente aquellos relacionados con la expansión regional de la disciplina.

Tabla 2. Ponencias por subdisciplina

\begin{tabular}{lcccc}
\hline \multicolumn{1}{c}{ Subdisciplina } & 2008 & 2010 & 2014 & Total general \\
\hline Conflicto & 54 & 41 & 91 & 186 \\
Políticas públicas & 33 & 35 & 87 & 155 \\
RR.II. & 42 & 28 & 57 & 127 \\
Sistemas electorales & 44 & 20 & 35 & 99 \\
Movimientos sociales & 27 & 17 & 40 & 84 \\
Teoría Política & 22 & 26 & 33 & 81 \\
Régimen político & 13 & 11 & 45 & 69 \\
Enfoques epistemológicos & 12 & 10 & 23 & 45 \\
Administración pública & 4 & 1 & 18 & 23 \\
Comportamiento político & 0 & 0 & 19 & 19 \\
Comunicación política & 2 & 0 & 10 & 12 \\
Teoría del Estado & 4 & 0 & 0 & 4 \\
Métodos & 0 & 0 & 1 & 1 \\
Política comparada & 0 & 0 & 1 & 1 \\
Total general & 257 & 189 & 460 & 906 \\
\hline
\end{tabular}

Fuente: elaboración propia. 


\section{UNA DISCIPLINA REGIONALIZADA}

En la actualidad, la formación profesional en Ciencia Política registra una creciente presencia en regiones distintas a Bogotá, ${ }^{7}$ como la Costa Atlántica (Atlántico y Bolívar), el Nordeste (Norte de Santander) y el Suroccidente (Cauca y Nariño), y en otros lugares del centro andino (Caldas, Huila, Tolima y Risaralda) (Fortou et al., 2013). Para entender los desafíos de esta dispersión geográfica en medio de la expansión, es necesario hacer una breve explicación geográfica y otra administrativa. En Colombia, un país con casi cincuenta millones de habitantes, la capital del país, Bogotá, solo concentra el 17\% de su población y las principales cinco ciudades (sin incluir sus áreas metropolitanas) concentran el 30\%, presentando 15 ciudades adicionales de más de 500.000 habitantes que distan muchas horas de viaje entre ellas, lo cual crea un mercado para la formación académica que está mucho más disperso y sin mucha influencia del centro.

Siguiendo a Guzmán (2013: 140),

"La Ciencia Política en el país, como disciplina profesional, viene (...) vislumbrando quizás el impacto de la política de descentralización implementada en el país a finales de la década de los años ochenta del siglo XX, la que posiblemente generó una demanda regional y local por los análisis de los procesos políticos, pero sin diálogo que la articulara. Respondió, sí, a iniciativas individuales y, en algunos casos, organizacionales, llenas de subjetividades y buenas intenciones personales e institucionales, más que a diálogos disciplinares que soportaran la apertura de los programas de Ciencia Política".

Aun así, el Gráfico 2 muestra que muchas regiones, especialmente las más apartadas, no cuentan con formación profesional en el área. El patrón que forma la distribución geográfica de la disciplina se puede sobreponer casi perfectamente sobre el recorrido de la cordillera de los Andes, con la excepción de los programas en Cartagena y Barranquilla (las ciudades más importantes de la costa caribe). Estas son las zonas que corresponden al área de mayor institucionalidad, riqueza y bienestar, aunque como se verá más adelante, no por eso con un desarrollo disciplinar homogéneo. Bogotá concentra el $40 \%$ de la oferta (incluyendo los tres únicos doctorados), Medellín el 17\%, seguido de Barranquilla, Cali, Ibagué, Manizales y Cartagena, cada una de estas ciudades con menos del $7 \%$ cada una. Por otro lado, como se puede ver en el mapa (Gráfico 2), más de la mitad del territorio no tiene un programa de pregrado o posgrado en Ciencia Política.

En la región suroccidental del país, el proceso de formación de la Ciencia Política inició en 1996 cuando se creó el pregrado de Ciencia Política en la Universidad del Cauca (Popayán); continuando años posteriores con la creación de pre y posgrados en instituciones como la Pontificia Universidad Javeriana, la Universidad del Valle y la Universidad ICESI en la ciudad de Cali. Pese al innegable avance que esto supone, resulta difícil hablar de una consolidación de la disciplina en esta región, en tanto: 
Gráfico 2. Distribución de los programas de Ciencia Política por Departamento

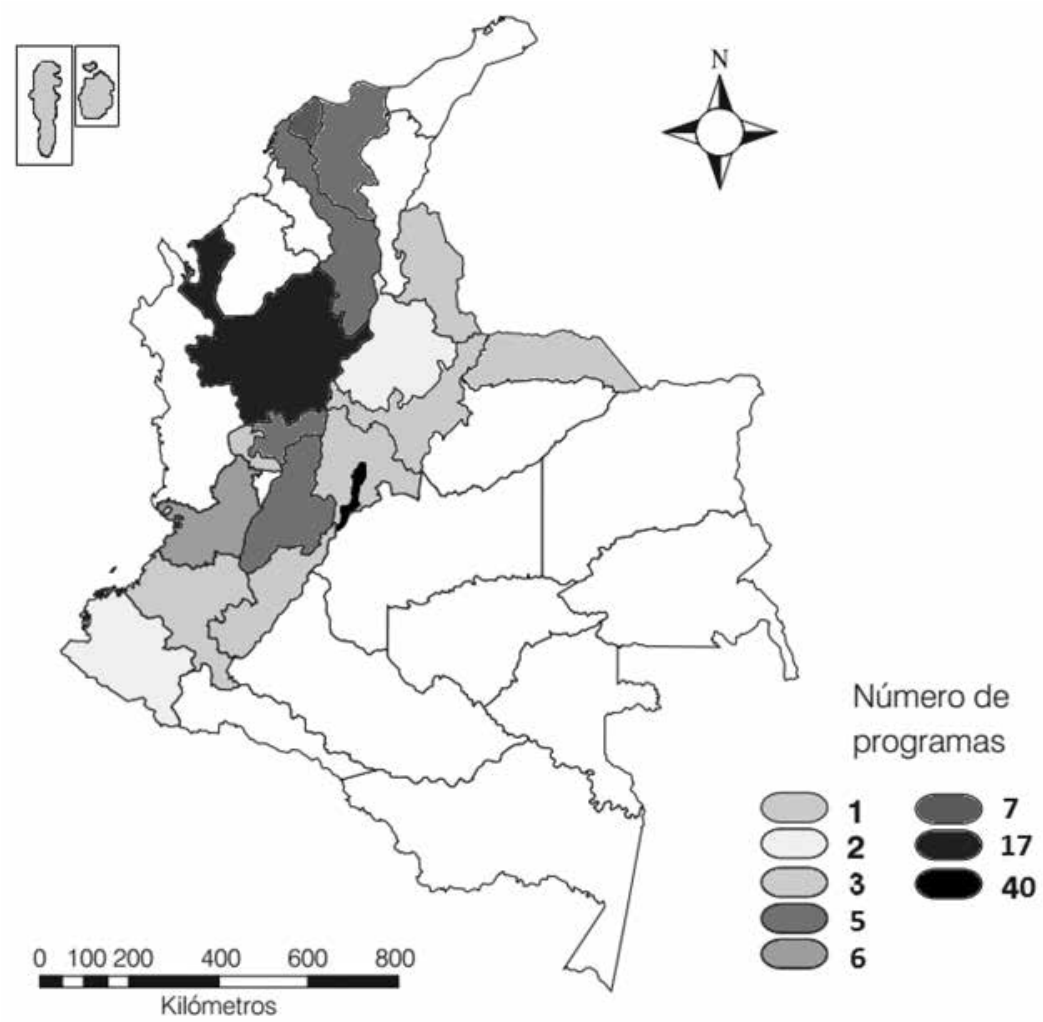

Fuente: Elaboración propia según datos del SNIES 2015.

"[...] los programas y sus respectivos departamentos tienen mucho que afirmar en términos de capacidad investigativa, de una mayor proyección y reconocimiento nacional e internacional, de una consolidación de activas y regulares redes locales y —especialmente- regionales y nacionales de trabajo (de debates e investigación)" (Milanese y Fernández, 2013: 137-138).

Algo similar se puede decir respecto de lo ocurrido en la costa atlántica, donde al hacer una reconstrucción de la historia regional de la disciplina a partir de los desarrollos de dos de sus principales universidades (Universidad Tecnológica de Bolívar y Universidad del Norte, ubicadas en Cartagena y Barranquilla respectivamente), se evidencia un proceso aún en vías de afianzamiento (Guzmán, 2013).

Otra de las historias regionales que vale la pena mencionar es la de Antioquia, una región cuyo punto de partida se ubica más temprano que el de las dos anteriores, pues en 1988 se dio la creación del Instituto de Estudios Políticos (IEP) de la Universidad de Antioquia (Medellín) y en 1990 la posterior apertura de la Maestría en Ciencia Política (Restrepo Parra et al., 2013). Es de resaltar, también, que a partir de la década del 2000 en 
Medellín se multiplica la oferta de programas de pregrado y posgrado en Ciencia Política tanto en instituciones públicas como privadas (en las universidades Nacional, Pontificia Bolivariana y EAFIT), hasta acumular hoy el $17 \%$ de todos los programas del país. Esta expansión ha ido acompañada de una especialización creciente en subdisciplinas y temas por universidad, aunque aún falta mucho en este camino para lograr diferenciarse.

En todos los casos mencionados, el avance disciplinar y la multiplicación de la oferta académica surgen como una respuesta a la necesidad de la sociedad regional de entender sus problemas políticos, sociales e institucionales. Aunque también lo hacen dentro de un mercado relativamente libre en el que las universidades buscan oportunidades para crecer. Puesto que se trata de respuestas locales que operan bajo una lógica de mercado, todos estos esfuerzos configuran un mapa de la Ciencia Política en el país bastante fragmentado, con asimetrías y diferencias significativas respecto de la manera en que se desarrolla la disciplina en cada región. Esta geografía de la disciplina se caracteriza también por una muy incipiente interacción entre pares de distintas ciudades, no obstante se ha dado un avance importante por la existencia de la ACCPOL y de los encuentros y congresos disciplinares. ${ }^{8}$

\section{UNA PROFESIÓN EN ASCENSO}

Respecto de la vida profesional y la inserción laboral de los politólogos, la información con que se cuenta en el país es escasa y poco sistemática. Para este apartado se tomaron como fuente de información los datos del Observatorio Laboral para la Educación, ${ }^{9}$ el trabajo no publicado de Casas et al. (2014) $)^{10}$ y la encuesta interna a egresados del Departamento de Gobierno y Ciencias Políticas de la Universidad EAFIT (2014). ${ }^{11}$

Según los datos del Observatorio, en Colombia se registra un significativo aumento en el número de graduados de Ciencia Política en cualquiera de los tres niveles de formación; ${ }^{12}$ reflejo entre otras cuestiones, de la multiplicación de la oferta. Entre 2001 y 2013 el número

8 Una de las formas en que se materializa esta fragmentación es la tendencia a realizar casos de estudio que describen la situación específica de un tema en una región, con muy poca presencia de trabajos comparados entre regiones de Colombia o del mundo. Esto se evidenció especialmente en la revisión realizada para este trabajo de las ponencias de los tres congresos realizados por la ACCPOL, como se mostrará más adelante.

9 Es un sistema de información especializado para el análisis de la pertinencia en la educación superior a partir del seguimiento a los graduados del país y su empleabilidad en el mercado laboral colombiano; depende del Ministerio de Educación Nacional.

10 Trabajo presentado en el III Congreso de Ciencia Política ACCPOL, en septiembre de 2014. Los autores aplicaron una encuesta física y electrónica a politólogos egresados de distintas universidades del país, la muestra fue de 126 egresados, por lo tanto los resultados no son conclusivos; a la fecha está en proceso de ampliación.

11 Trabajo presentado en el Encuentro con egresados de Ciencias Políticas de la Universidad EAFIT en noviembre de 2014. En el estudio se muestran los resultados de una encuesta dirigida a todos los egresados (muestra del $25 \%$ ) y de un grupo focal, con el propósito de conocer su inserción profesional.

12 La información del Observatorio está categorizada por NBC (núcleo básico del conocimiento), en este caso se trata del NBC Ciencia Política y Relaciones Internacionales que incluye los pregrados de Relaciones Internacionales, Política, Gobierno, Estudios Políticos, Ciencias Políticas. Las diferencias entre estos nombres (presentes en el Gráfico 3) no implican una clasificación temática por parte del Ministerio, sino una agrupación de acuerdo con el nombre dado por las universidades a sus programas. 
de graduados a nivel de pregrado alcanzó casi siete mil profesionales, siendo Relaciones Internacionales y Ciencia Política (Política en el gráfico), los denominadores con mayor número de graduados (ver Gráfico 3). Los datos también evidencian la consolidación de denominaciones como Relaciones Internacionales y Ciencia Política, frente a otras que eran más comunes 10 años atrás como Estudios Políticos y Ciencias Políticas (en plural). Igualmente, muestran el dinamismo que han tenido los nuevos programas de gobierno, especialmente a nivel de maestría. Finalmente, el Gráfico 3 ilustra que desde 2010 se gradúan un promedio de 1.600 egresados al año, el doble de los que se graduaban en 2005. Todo esto permite plantear que la disciplina ha ido encontrando nichos de formación que, como se verá más adelante, se conectan con el mercado laboral.

Si se toman en cuenta los datos comparados al 2012 de la tasa de cotizantes a seguridad social (pensiones y salud) y los ingresos promedio de los graduados de varias profesiones afines, se observa que el 71,7\% de los recién graduados de Ciencia Política están vinculados formalmente al mercado laboral, porcentaje levemente inferior al de profesiones de mayor tradición (Derecho: 73,5\%) y consolidación académica (Sociología: 71,9\%) en el país. Estos datos muestran cierta coincidencia con los de Casas et al. (2014), según los cuales un $78 \%$ de politólogos manifestaban estar empleados al momento de ser encuestados. Respecto del promedio de ingresos mensuales de los recién egresados, se encuentra que para los politólogos es de \$1.929.471 (entre USD 800 y USD 1.000), ligeramente menor que el de los abogados y levemente superior al de los sociólogos.

Lo anterior sugiere que el mercado laboral aún no estaría saturado (como ocurre con otras profesiones), más bien se podría afirmar que también está en expansión. Esto se

Gráfico 3. Número de graduados de pregrado por año

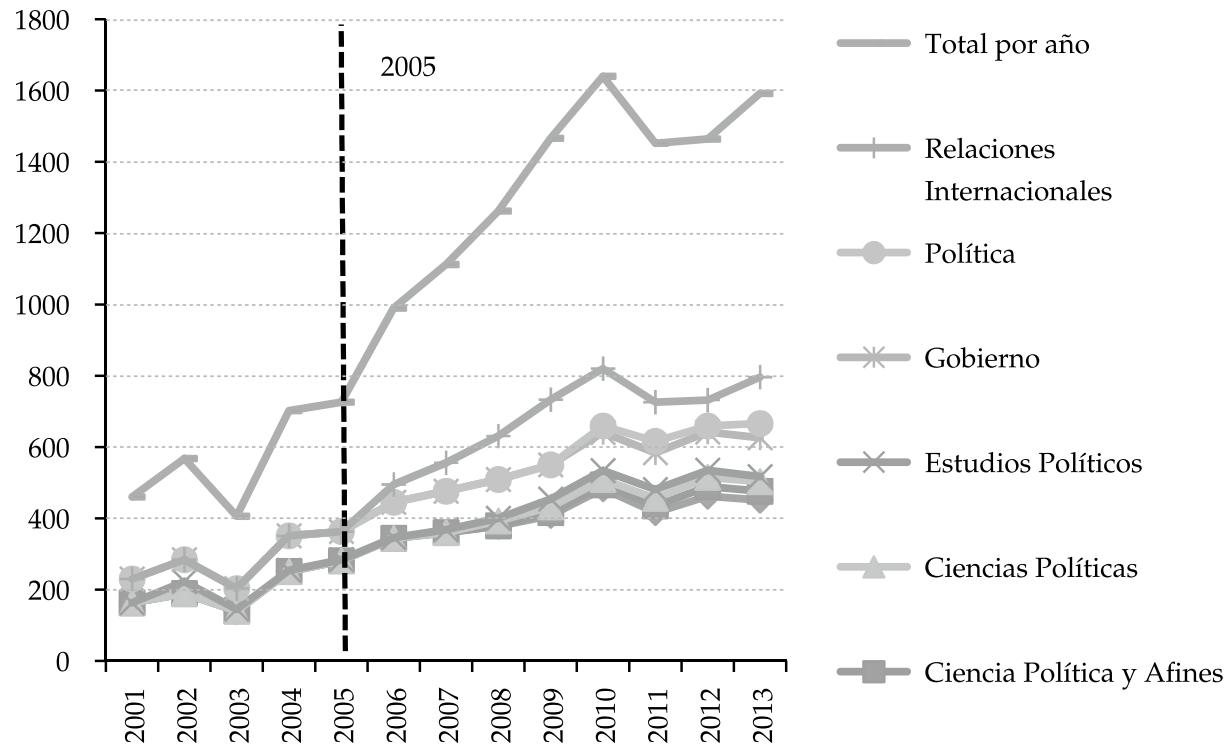

Fuente: Elaboración propia según datos del Observatorio Laboral 2015. 
debe, entre otros factores, a que en las últimas dos décadas la descentralización y los cambios institucionales a partir de la Constitución de 1991, llevaron a que creciera la demanda de profesionales para la gestión pública en todos los niveles de gobierno. Asimismo, se ha generado una mayor sofisticación en las organizaciones de la sociedad civil que actualmente buscan incidir de manera creciente sobre las políticas públicas y en la agenda política, requiriendo profesionales de la política para una acción efectiva. Por otro lado, los procesos de mediatización de la política y el uso extendido de redes sociales como nuevos canales de comunicación política amplían la oferta laboral para los politólogos. Adicionalmente, diversas empresas, tanto públicas como privadas, particularmente del sector energético y minero, hoy en día incluyen a politólogos en su planta a fin de realizar análisis de riesgo sociopolítico.

A pesar de que los datos de inserción profesional son alentadores, no se pueden desconocer ciertas dificultades en este proceso, debido a condiciones de precariedad contractual o restricciones estructurales para el acceso a determinados nichos laborales. Por ejemplo, en el sector público, la profesionalización del servicio civil es una asignatura pendiente en Colombia (ver Isaza, 2014), extendiéndose la figura del contratista caracterizado por la inestabilidad laboral y unas condiciones poco atractivas en términos salariales y de proyección profesional. Otro factor relevante -señalado por Leiras et al. (2005: 86) en el caso argentino- que aplicaría también para el colombiano, es que "muchas veces los empleadores desconocen cuáles son los saberes específicos de las politólogas y los politólogos", lo que hace que el avance en la inserción laboral se haya tenido que dar paso a paso y con mucho apoyo de las universidades.

En el proceso de garantizar una mejor inserción laboral ha surgido también la discusión respecto de la necesidad de una regulación de la profesión de politólogo en el país. Desde 2012 se registran algunos intentos de regular la actividad por la vía legislativa, los que han recibido fuertes críticas desde algunos sectores de la academia y la ACCPOL. ${ }^{13}$ Entre otros puntos polémicos, está la no equiparación del título de politólogo por títulos de posgrado en áreas relacionadas con la ciencia política y la creación de un órgano rector encargado de expedir la tarjeta profesional y el llamado Código de Ética Profesional, actuar como Tribunal de Ética y acreditar las asociaciones de politólogos en el país, entre otras funciones. Una de las inquietudes que suscita este tipo de proyectos es que determinados actores políticos tengan vía libre para controlar, censurar y sancionar el ejercicio de unos profesionales que, justamente, inciden en los procesos políticos. Por otra parte, se podría argüir la falta de necesidad de regular una profesión de la cual no se desprende un riesgo para la sociedad. No obstante los argumentos previos, no se pueden desconocer algunas ventajas puntuales de llevar a cabo la regulación, por ejemplo, la existencia de una tarjeta profesional que permitiría, entre otras cosas, una más clara inclusión de la profesión en los procesos de convocatoria del servicio civil, muchas veces cerrados a actividades reguladas como el Derecho. Igualmente, se podría

13 Es decir, estas iniciativas no provienen directamente de la ACCPOL o de un grupo organizado de politólogos, sino de congresistas específicos (con o sin politólogos cercanos) que actúan a título individual y sin una agenda clara para la comunidad politológica. 
pensar en los beneficios de tener algunas materias comunes y unas habilidades mínimas de carácter práctico que sean reconocidas públicamente.

La discusión está instalada y hace parte del proceso de institucionalización de la disciplina. Lo cierto es que los politólogos y la ACCPOL han operado de manera reactiva de cara a estas iniciativas, lo cual evidencia la ausencia de una contrapropuesta que lidere el debate en el país. En ese orden de ideas, en el futuro cercano se debería dar un mayor trabajo en red entre las instituciones que imparten formación en Ciencia Política, la ACCPOL, los empleadores y los propios egresados, a fin de articular esfuerzos que permitan identificar con claridad el lugar del politólogo en el mercado y sus competencias diferenciales respecto de otro profesional de las Ciencias Sociales. En este punto, vale la pena resaltar que la situación descrita debe asumirse "como una descripción de las dificultades que enfrenta una disciplina en crecimiento más que como el diagnóstico de un saber en declinación" (Leiras et al., 2005: 87).

\section{VI. ¿QUÉ CONOCIMIENTO SE PRODUCE EN LA DISCIPLINA?}

Una vez revisados los aspectos ligados a la comunidad, la formación, la regionalización y la profesión, en este apartado se hace referencia a las tendencias temáticas que se identifican en la producción disciplinar, a partir de la construcción de una base de datos de publicaciones que incluye 730 artículos de revista y 239 libros en el período 2005-2014.

Para seleccionar los libros, se tuvieron en cuenta todos los títulos disponibles en los portales electrónicos de las universidades colombianas con producción en temas de Ciencia Política, Estudios Políticos y Relaciones Internacionales. Por lo tanto, solo aparecen aquellos libros susceptibles de consulta en las páginas web de las instituciones. Por otra parte, el criterio de selección de las revistas de Ciencia Política, que sirvieron de muestra para los propósitos de la investigación, fue el posicionamiento en el Índice Bibliográfico Nacional - IBN Publindex I (Actualización 2014). La revisión realizada arrojó cuatro revistas de la disciplina que se encuentran en categoría A2. Dichas revistas son: Análisis Político, Colombia Internacional, Papel Político y Estudios Políticos. La primera de ellas pertenece a la Universidad Nacional de Colombia, la segunda a la Universidad de los Andes, la tercera a la Universidad de Antioquia y la cuarta a la Universidad Javeriana. Cabe anotar que dos de las revistas pertenecen a universidades públicas y las otras dos a universidades privadas. También, es importante resaltar que dos de las cuatro revistas (Colombia Internacional y Análisis Político) se encuentran indexadas en ISI y Scopus.

De la elección de las subdisciplinas usadas en la elaboración de la base de datos se retomaron las categorías disciplinares propuestas por: Leal Buitrago y Dávila, en el artículo "Estudios políticos en Colombia 1970-1987" (1988); Bejarano y Wills, en su texto "La Ciencia Política en Colombia: de vocación a disciplina" (2005); el "Nuevo curso de Ciencia Política" de Pasquino (2011); la clasificación de Goodin y Klingemann (1996) y de Goodin (2010) en los Manuales de Ciencia Política de Oxford; y las respectivas clasificaciones de IPSA (International Political Science Association) y las líneas temáticas de los congresos de ACCPOL. A partir de esta información y con su respectivo cotejo, se 
seleccionaron las clasificaciones más generales e integradoras, de tal forma que se diera cuenta de todas las líneas temáticas que se proponen -nacional e internacionalmentepara el estudio de la Ciencia Política (ver Tabla 3).

Tabla 3. Clasificaciones generales de las subdisciplinas de la Ciencia Política

\begin{tabular}{ll}
\hline \multicolumn{1}{c}{ Categorías resultantes } & \multicolumn{1}{c}{ Denominador utilizado } \\
\hline $\begin{array}{l}\text { Relaciones internacionales } \\
\text { Conflicto armado, seguridad, construcción de paz y }\end{array}$ & RR.II. \\
posconflicto & Conflicto \\
Políticas públicas & Políticas públicas \\
Teoría política & Teoría política \\
Movimientos sociales, reconocimientos y diversidades & Movimientos sociales \\
Sistemas electorales, partidos políticos y representación & Sistemas electorales \\
amplia & Comportamiento político \\
Comportamiento político & Régimen político \\
Régimen político & Política comparada \\
Política comparada & Enfoques \\
Enfoques epistemológicos & Administración pública \\
Administración pública & Comunicación política \\
Comunicación política & Teoría del Estado \\
Teoría del Estado & \\
\hline
\end{tabular}

Fuente: elaboración propia.

En primer lugar, el análisis de la base de datos muestra que la subdisciplina de RR.II. es la que evidencia la mayor presencia, con 144 artículos y 56 libros. La revista que más publica artículos sobre RR.II. es Papel Político (54), seguida por Análisis Político (43), Colombia Internacional (37) y en último término Estudios Políticos (10). Estos datos son congruentes con el prestigio y fortalecimiento creciente de las RR.II. en Colombia -que algunos consideran una disciplina en sí misma-, proceso que se ve favorecido, entre otros factores, por la difusión del trabajo que vienen desarrollando diversas universidades y la Red Colombiana de Relaciones Internacionales (RedIntercol). En el despegue de las RR.II. tiene mucho que ver la alta demanda que experimentan las universidades por estos programas, especialmente las privadas. Esto ha facilitado la expansión de las plantas docentes y un gran dinamismo académico que, entre otras cosas, ha permitido generar un encuentro subdisciplinar que tendrá en 2015 su cuarta versión.

En segundo lugar, el estudio del Conflicto es la segunda subdisciplina más trabajada con 106 artículos y 52 libros en el período evaluado. Solo en 2013 se produjeron 22 artículos y cuatro libros, debido la centralidad que han cobrado los diálogos en La Habana con las FARC. Una de las preguntas que subyace en estos artículos es: ¿qué es lo que hace que el conflicto colombiano se haya prolongado por tanto tiempo y lo siga haciendo? 
Tabla 4. Publicaciones completas de libros y revistas de Ciencia Política 2005-2014

\begin{tabular}{|c|c|c|c|c|c|c|c|}
\hline & \multirow[b]{2}{*}{ Libros } & \multicolumn{4}{|c|}{ Revistas } & \multirow{2}{*}{$\begin{array}{c}\text { Total } \\
\text { Revistas }\end{array}$} & \multirow{2}{*}{$\begin{array}{c}\text { Total } \\
\text { general }\end{array}$} \\
\hline & & $\begin{array}{l}\text { Análisis } \\
\text { Político }\end{array}$ & $\begin{array}{c}\text { Colombia } \\
\text { Internacional }\end{array}$ & $\begin{array}{l}\text { Estudios } \\
\text { Políticos }\end{array}$ & $\begin{array}{c}\text { Papel } \\
\text { Político }\end{array}$ & & \\
\hline RR.II. & 56 & 43 & 37 & 10 & 54 & 144 & 200 \\
\hline Conflicto & 53 & 51 & 25 & 15 & 15 & 106 & 159 \\
\hline $\mathrm{N} / \mathrm{A}$ & 17 & 14 & 15 & 35 & 25 & 89 & 106 \\
\hline Políticas públicas & 23 & 16 & 8 & 12 & 23 & 59 & 82 \\
\hline Sistemas electorales & 16 & 16 & 20 & 14 & 9 & 59 & 75 \\
\hline Teoría política & 18 & 3 & 8 & 25 & 21 & 57 & 75 \\
\hline Movimientos sociales & 18 & 7 & 17 & 14 & 9 & 47 & 65 \\
\hline Régimen político & 14 & 14 & 9 & 10 & 13 & 46 & 60 \\
\hline Administración pública & 2 & 9 & 5 & 11 & 11 & 36 & 38 \\
\hline Comportamiento político & 14 & 6 & 5 & 7 & 6 & 24 & 38 \\
\hline Política comparada & 6 & 11 & 6 & 4 & 9 & 30 & 36 \\
\hline Enfoques epistemológicos & 4 & 2 & 3 & 2 & 3 & 10 & 14 \\
\hline Comunicación política & 1 & 4 & 2 & 1 & 4 & 11 & 12 \\
\hline Teoría del Estado & 1 & 2 & 2 & 1 & 5 & 10 & 11 \\
\hline Métodos & 0 & 0 & 2 & 0 & 0 & 2 & 2 \\
\hline Total & 243 & 198 & 164 & 161 & 207 & 730 & 973 \\
\hline
\end{tabular}

Fuente: elaboración propia.

Además, los trabajos evaluados muestran un interés por la llegada de los dineros del narcotráfico a la política y el surgimiento de la llamada parapolítica. Este último fenómeno ha dejado claro que las élites regionales todavía tienen suficientes bases de poder propio, como para que el centro político les tenga que delegar la gestión del territorio (González, 2014; Gutiérrez, 2014). Además, existen otras zonas suficientemente marginadas y con economías "ilegales" tan fuertes como para poder ser administradas de facto por contrapoderes armados (Giraldo, 2013; Duncan, 2014). Empujando un poco este hallazgo, se puede decir que para la Ciencia Política colombiana el reto ha sido describir estos procesos informales de soberanías en disputa, de construcción del Estado en contraposición con poderes informales con cierta legitimidad sociopolítica (no jurídica), con lo cual el aporte en esta década siguió siendo la creación de categorías descriptivas que le podrían resultar interesantes a muchos académicos en América Latina.

En tercer lugar en volumen se sitúan los estudios de Políticas públicas. De hecho, uno de los cambios más notorios de los últimos diez años fue la aparición de la subdisciplina de las políticas públicas, cuyos primeros textos son del inicio de la década (ver Roth, 2002). Esta irrupción de un nuevo campo se hizo visible cuando, en el primer congreso de ACCPOL en el 2007, los organizadores se vieron forzados a crear una línea para acomodar la gran cantidad de ponencias recibidas sobre el tema. Su dinamismo se 
refleja también en la producción de 59 artículos y 23 libros, así como en la consolidación de un doctorado con este énfasis en la Universidad Nacional de Colombia (sede Bogotá) desde donde se ha organizado la producción de varios libros con artículos de académicos de todo el país. Igualmente, se han construido redes regionales en varias ciudades y en los últimos cinco años se ha dado una bonanza de maestrías de gobierno en universidades de todo el país. Este surgimiento quizás se deba en parte a la influencia del neoinstitucionalismo como enfoque epistemológico en la Ciencia Política en general, interés que le ha dado una nueva vitalidad a los estudios sobre el Estado, las burocracias y las políticas públicas (v.gr. Uribe, 2013; García et al., 2011). Otra hipótesis sobre el crecimiento de esta área tiene que ver con la búsqueda de salidas al conflicto y la crisis colombiana del fin de siglo, como ilustra por ejemplo la amplia discusión que se le dio a la política de "Seguridad Democrática" de la época del presidente Uribe (2002-2010). Finalmente, este auge también denota el interés por entender los efectos de los cambios en el régimen territorial (descentralización) sobre el orden político, aunque siempre de manera muy descriptiva.

Cercana a la anterior, se sitúa también la subdisciplina Sistemas electorales, área que fue durante muchos años, por lo menos hasta los ochenta, la de mayor desarrollo teórico y metodológico en la Ciencia Política colombiana (ver Botero, 2010). En los últimos diez años, una buena parte de los trabajos analizaron elecciones puntuales y se concentraron en ver el efecto unificador de las reformas políticas sobre la fragmentación partidista de finales de los años noventa. Este foco institucionalista mostró la reagrupación del sistema de partidos después de los cambios en el umbral, pero llevó a que pocos trabajos miraran a los partidos por dentro o examinaran las particularidades de la política regional (Gutiérrez, 2007). Una innovación en este campo fue la conexión entre los temas formales del sistema de partidos con el mundo no formal, ilegal y criminal.

Dejando atrás el análisis de los temas y haciendo un zoom en la producción de libros se puede observar en la Tabla 5 que "el estudio de la violencia" que arrancó entre finales de los años ochenta y principios de los noventa en el IEPRI de la Universidad Nacional (Bejarano y Wills, 2005: 115), el IEP de la Universidad de Antioquia y el CINEP, se volvió la tendencia general de la Ciencia Política colombiana, asunto que se resume bien por el hecho de que la Universidad de los Andes (caracterizada una década atrás por la producción sobre partidos y elecciones) publica hoy más libros sobre este tema que de otras áreas (ver Tabla 5). Esta dinámica ha permeado casi todas las áreas de la Ciencia Política, debido a que si se habla hoy de Comportamiento político, Teoría política, incluso de Política comparada, necesariamente se exploran en Colombia las interacciones de estas mismas áreas con el conflicto, el narcotráfico y la corrupción.

Para entender por qué la politología colombiana se interesa por el conflicto, resulta conveniente recordar, como señalan Munck y Snyder (2007) en su libro sobre los grandes pioneros de la Ciencia Política norteamericana, que la generación que vivió la época del fascismo y de las grandes guerras mantuvo un gran interés por evitar su reaparición. Es decir que, en estos autores, se dio una conexión entre el contexto, la experiencia vital de los cultores de la disciplina y sus temas de investigación. En paralelo, a la mayoría 


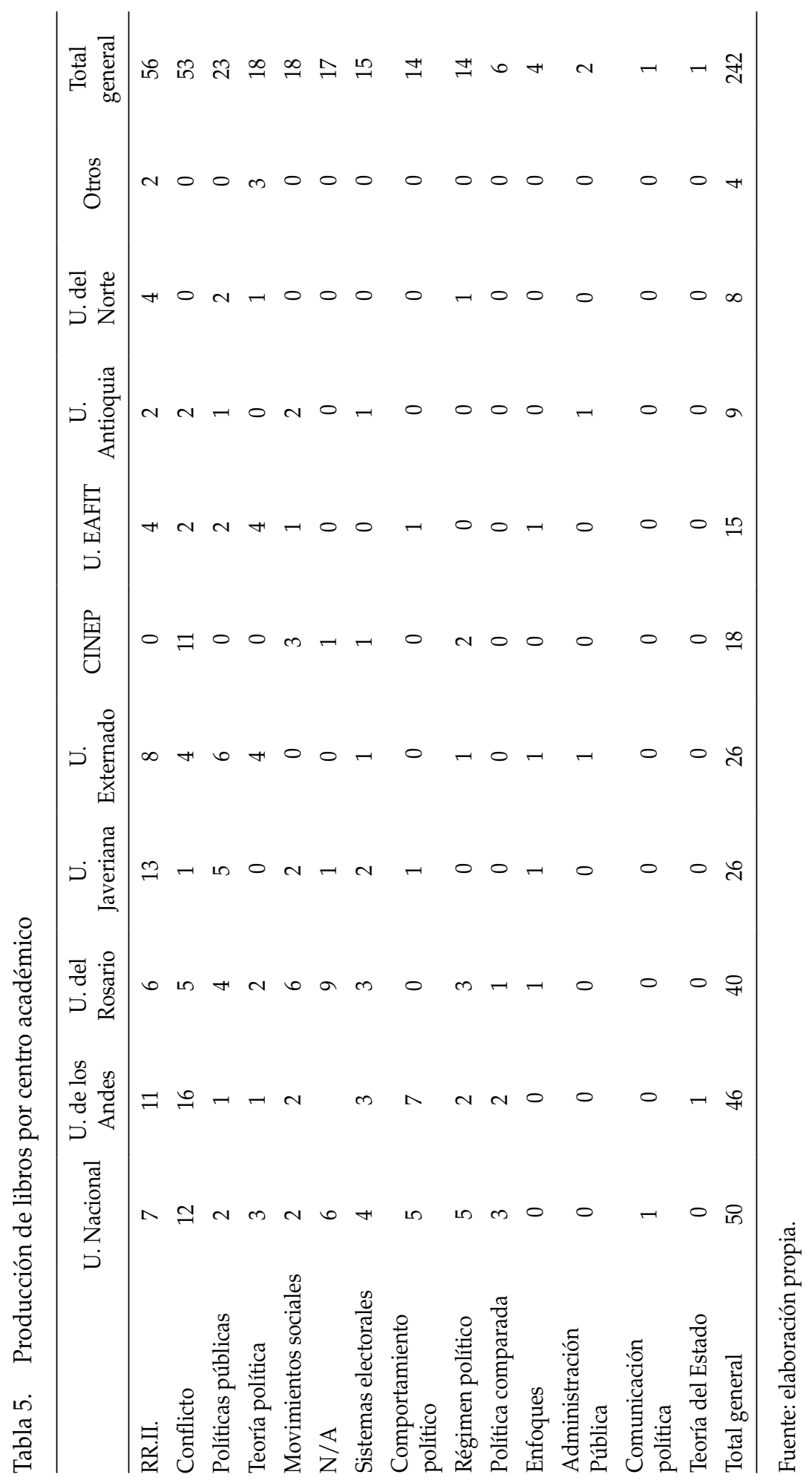


de los politólogos colombianos les ha tocado vivir de primera mano el fenómeno de la violencia, la insurgencia y la crisis de la seguridad causada por el narcotráfico, las guerrillas y la criminalidad, lo que los lleva naturalmente a profundizar en estos asuntos.

\section{UNA DISCIPLINA DESCRIPTIVA, CUALITATIVA Y ENDÓGENA}

Para profundizar en la caracterización de la producción de conocimiento en Ciencia Política en el país, se procedió a clasificar los artículos de la base de datos con categorías que permitieran diferenciarlos. Se utilizaron las tipificaciones propuestas por Rivera y Salazar-Elena (2011) correspondientes a las relaciones 'Descriptivo vs. Causal', 'Cualitativo vs. Cuantitativo'; se identificó también el número de 'Cobertura de casos' y se exploró la 'Cobertura espacial'. Para realizar esta exploración se retomó la mayoría del procedimiento aplicado para México por Rivera y Salazar-Elena (2011), así como el trabajo de Munck y Snyder (2007b).

El análisis realizado empezó por la clasificación de los trabajos entre descriptivos y causales. Para ello, se diferenció entre los estudios que se preocupan por establecer el porqué de los fenómenos observados (procedimiento causal) respecto de aquellos que se preocupan por describirlos (investigaciones descriptivas). Es importante aclarar que no se asume que lo causal solo es cuantitativo a la manera de King et al. (1996), sino que también se acepta el poder explicativo en términos causales de las investigaciones cualitativas, como lo expresa el enfoque de los métodos mixtos (Mahoney y Goertz, 2012), siempre y cuando los trabajos descriptivos manifiesten explícitamente este propósito.

Como se puede observar en la tabla 6, la producción de artículos descriptivos (583 artículos; $91 \%$ del total) es muy superior a la de artículos con una explicación causal (52 artículos; $8 \%$ del total). La subdisciplina que más se inclina hacia la inferencia causal es Sistemas electorales, seguida por Política comparada y Comportamiento político. Las demás subdisciplinas cuentan con un porcentaje menor al 10\% de los artículos con exploraciones causales. En ese sentido, se evidencia un desequilibrio, pues por cada artículo causal se producen en Colombia 11,2 descriptivos. A manera de ilustración, esta misma proporción es de 1,1 en Estados Unidos (Munck y Snyder, 2007a: 11) y de 2,21 en México (Rivera y Salazar-Elena, 2011: 85). Esto sugiere que en Colombia existe un claro desbalance a favor de los trabajos descriptivos, mucho más acentuado que en un país como México.

En este mismo orden de ideas se determinó la diferenciación entre tipo de métodos 'Cuantitativo vs. Cualitativo'. Así, los artículos que se basaban en procedimientos estadísticos y procesamientos de datos para explicar la realidad se identificaron como cuantitativos. El resto, incluso aquellos que emplean tablas de frecuencias de manera ilustrativa, se agruparon como cualitativos. Esto sin duda es una gran generalización, debido a que se incluyen en la misma categoría a los artículos especulativo-reflexivos de carácter más filosófico y aquellos más empíricos. Sin embargo, se asume en este artículo que la categoría resulta ilustrativa de las tendencias gruesas de la disciplina en el país. 
Tabla 6. Análisis descriptivo versus causal

\begin{tabular}{lccccc}
\hline \multirow{2}{*}{\multicolumn{1}{c}{ Subdisciplinas }} & \multicolumn{5}{c}{ Tipo de análisis de datos } \\
\cline { 2 - 6 } & Causal & Descriptivo & N/A & Total general & $\begin{array}{c}\text { Causal / } \\
\text { Total }\end{array}$ \\
\hline Sistemas electorales & 15 & 44 & 0 & 59 & $25 \%$ \\
Política comparada & 7 & 23 & 0 & 30 & $23 \%$ \\
Comportamiento político & 3 & 21 & 0 & 24 & $13 \%$ \\
Comunicación política & 1 & 10 & 0 & 11 & $9 \%$ \\
Movimientos sociales & 4 & 42 & 1 & 47 & $9 \%$ \\
Administración pública & 3 & 33 & 0 & 36 & $8 \%$ \\
Conflicto & 7 & 98 & 1 & 106 & $7 \%$ \\
RR.II. & 9 & 134 & 1 & 144 & $6 \%$ \\
Régimen político & 1 & 45 & 0 & 46 & $2 \%$ \\
Teoría política & 1 & 53 & 3 & 57 & $2 \%$ \\
Políticas públicas & 1 & 58 & 0 & 59 & $2 \%$ \\
Enfoques epistemológicos & 0 & 10 & 0 & 10 & $0 \%$ \\
Métodos & 0 & 2 & 0 & 2 & $0 \%$ \\
Teoría del Estado & 0 & 10 & 0 & 10 & $0 \%$ \\
Total general & 52 & 583 & 6 & 641 & $8 \%$ \\
\hline
\end{tabular}

Fuente: elaboración propia, adaptado de Rivera y Salazar-Elena (2011).

Tabla 7. Análisis cualitativo versus cuantitativo

\begin{tabular}{lccccc}
\hline \multirow{1}{*}{\multicolumn{1}{c}{ Subdisciplina }} & \multicolumn{5}{c}{ Tipo de métodos } \\
\cline { 2 - 6 } & Cuantitativo & Cualitativo & N/A & Total & $\begin{array}{c}\text { Cuantitativo / } \\
\text { Total }\end{array}$ \\
\hline Sistemas electorales & 20 & 39 & 0 & 59 & $34 \%$ \\
Comportamiento político & 8 & 16 & 0 & 24 & $33 \%$ \\
Comunicación política & 3 & 8 & 0 & 11 & $27 \%$ \\
Política comparada & 7 & 23 & 0 & 30 & $23 \%$ \\
Políticas públicas & 8 & 51 & 0 & 59 & $14 \%$ \\
Conflicto & 12 & 93 & 1 & 106 & $11 \%$ \\
Movimientos sociales & 5 & 41 & 1 & 47 & $11 \%$ \\
Enfoques epistemológicos & 1 & 9 & 0 & 10 & $10 \%$ \\
Administración pública & 3 & 33 & 0 & 36 & $8 \%$ \\
Régimen político & 2 & 44 & 0 & 46 & $4 \%$ \\
RR.II. & 6 & 137 & 1 & 144 & $4 \%$ \\
Métodos & 0 & 2 & 0 & 2 & $0 \%$ \\
Teoría del Estado & 0 & 10 & 0 & 10 & $0 \%$ \\
Teoría política & 0 & 56 & 1 & 57 & $0 \%$ \\
Total general & 75 & 562 & 4 & 641 & $12 \%$ \\
\hline
\end{tabular}

Fuente: elaboración propia, adaptado de Rivera y Salazar-Elena (2011). 
En esta categoría se observa una mayoría de artículos cualitativos (562 artículos; 88\% del total) frente a los cuantitativos (75 artículos; $12 \%$ del total). Al igual que en la clasificación 'Descriptivo vs. Causal', la subdisciplina que cuenta con mayor cantidad de estudios cuantitativos es Sistemas electorales, seguida por Comportamiento Político y Comunicación Política. También es de resaltar que ningún artículo de Teoría Política, Teoría del Estado y de Métodos es de carácter cuantitativo, lo cual es coherente con la naturaleza de al menos las dos primeras subdisciplinas. En general, los artículos clasificados como cuantitativos llegan a $12 \%$, esto es, por cada artículo cuantitativo se producen 7,49 artículos cualitativos; proporción que en México equivale a 11,19 y en Estados Unidos a 0,78, ya que en este último país se producen un 56,1\% de artículos cuantitativos (Schedler y Mudde, 2010; citado en Rivera y Salazar-Elena, 2011: 86).

Por otro lado, a fin de verificar la presencia de trabajos comparados en la Ciencia Política colombiana, se estableció la codificación por cobertura de casos, usando como elemento diferenciador la cantidad de casos examinados por el libro o artículo clasificado. En las categorías de 'Cobertura espacial' y 'Cobertura de casos' se optó por usar N/A para aquellos estudios que no tuvieran una de las opciones definidas, esto es, para las investigaciones para las cuales no se pudiera determinar una cobertura espacial o una cobertura de casos específica.

De la muestra, el 67,9\% de los trabajos corresponden a estudios de caso. La subdisciplina con mayor cantidad de estudios de caso totales (87\%) es de lejos Política comparada, lo que se explica por su propio objeto y método. Muy distantes le siguen RR.II. y Régimen político que tienen un $21 \%$ y $17 \%$ respectivamente, de trabajos que abordan más de un caso. Esta ausencia implicaría que el reto de la Ciencia Política en Colombia es preocuparse un poco más por el avance disciplinar y un poco menos por explicar la especificidad del contexto. Posiblemente, ahora que Colombia ha dejado de ser el outlier latinoamericano en términos de seguridad, se puedan empezar a realizar más trabajos comparados. Es probable también que el detonante en esta dirección sea la mayor presencia de politólogos colombianos en los congresos de ALACIP, lo cual se vio reforzado con la realización del evento de 2013 en Bogotá.

Para concluir esta sección es importante aclarar que con este análisis no se pretende establecer una estratificación del trabajo investigativo en la Ciencia Política entre lo cualitativo y lo cuantitativo. Se trata más bien de reconocer que hay un vacío en la producción de trabajos causales, comparativos y mixtos, que en el fondo expresan una debilidad metodológica en el país en estas áreas. La Ciencia Política colombiana en la última década ha sido rica en trabajos que buscan comprender una realidad abierta y poco institucionalizada, como la del conflicto armado, la de los espacios informales donde el Estado no es soberano y los entornos desinstitucionalizados donde los partidos políticos son meras ficciones. Pero en el futuro será importante que también se extienda el uso de metodologías mixtas para identificar regularidades e incluso compararlas, con el fin de entender más sobre sus causas y efectos en entornos más estables. 


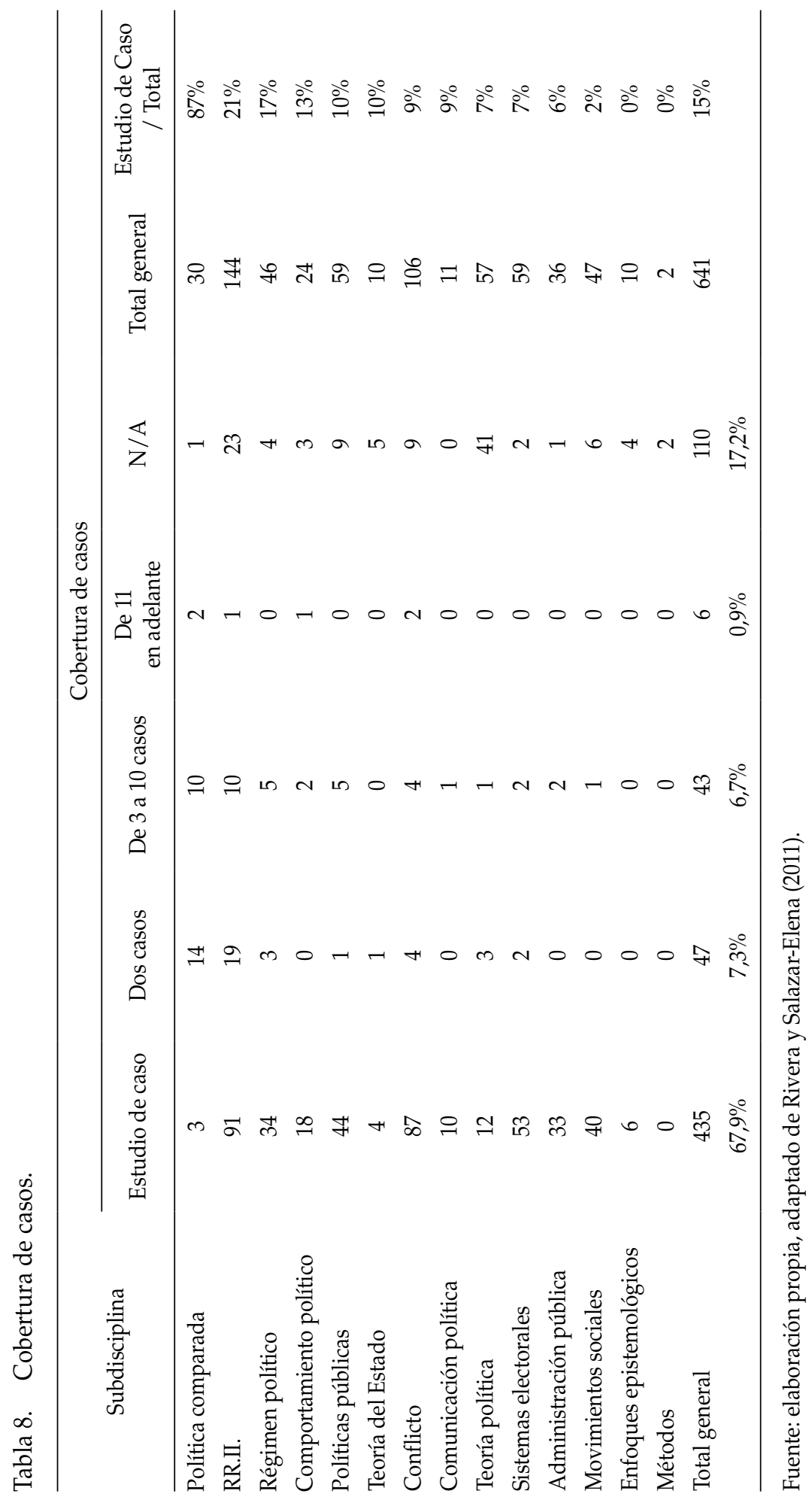




\section{CONCLUSIONES}

Hace diez años Bejarano y Wills (2005) hablaban del "crecimiento y diversificación" de la Ciencia Política Colombiana desde 1990 hasta 2005. Entre 2006 y el 2015 el crecimiento continuó acumulando $219 \%$ a nivel de pregrados y $173 \%$ a nivel de posgrados, es decir, un promedio cercano a $20 \%$ al año. Este ritmo se puede calificar como de expansión acelerada y está ligado no solo a la entrada cada vez más evidente de la disciplina a los medios masivos y al imaginario popular, sino también a ciertos factores estructurales como la ampliación de la cobertura universitaria en Colombia en términos generales.

El mismo proceso llevó a que la disciplina prosiguiera con su proceso de descentralización, llegando en estos años a ocho nuevas ciudades. No obstante, el peso de Bogotá duplica a la segunda ciudad y el de Medellín, casi triplica a la tercera. En este sentido, la formación disciplinar replica los patrones comunes a muchas otras áreas y que de alguna manera son un reflejo de la fortaleza institucional diferenciada de los territorios en Colombia. Por esto, si Bejarano y Wills (2005) depositaban su esperanza en que la aparición de un congreso disciplinar le iba a poner fin a las "islas", diez años después parece necesario enfatizar que las asimetrías están ligadas a las del país, resaltando en este punto que la formación en Ciencia Política todavía no hace presencia en la mitad de Colombia.

Por otra parte, se debe destacar la aparición de la ACCPOL y la celebración de los tres congresos y los dos encuentros. Pero aún se requiere más protagonismo por parte de la Asociación, por ejemplo, en cuestiones relativas a la regulación profesional, el mejoramiento de la calidad de los pregrados y posgrados y la inserción laboral. Cabe recordar que hasta el momento todas las iniciativas de regulación han llegado desde afuera, representando un riesgo importante para el futuro de un quehacer que convoca a varias profesiones y cuyo "control" puede ser tan deseable para algunos sectores políticos.

Respecto de la producción de conocimiento en Ciencia Política se ha notado la importancia de los temas asociados con las relaciones internacionales y el conflicto armado. Se evidenció, además, el surgimiento de la literatura de políticas públicas y el mayor avance metodológico de los trabajos cuantitativos acerca de los partidos políticos. Del análisis de las publicaciones se concluye que hace falta fortalecer los estudios cuantitativos y causales en Colombia, sin que esto lleve a perder o a subvalorar la rica tradición descriptiva que existe en el país. Asimismo, se debería ampliar la presencia de estudios cualitativos con preguntas causales, asunto que se ha retomado en la Ciencia Política actual bajo el nombre de métodos mixtos (Mahoney y Goertz, 2012). En síntesis, una Ciencia Política que avanza, aunque de manera diferenciada y regionalizada, como profesión, como comunidad y como generadora de conocimiento, pero eminentemente descriptiva, cualitativa, monográfica y no comparada. ${ }^{14}$

14 Algo similar se dice sobre el caso mexicano por los autores que diseñaron la metodología acá utilizada, “contrario a las creencias sobre la americanización de la Ciencia Política mexicana, los resultados muestran que esta es dominantemente descriptiva, monográfica y cualitativa" (Rivera y Salazar-Elena, 2011: 73). 


\section{REFERENCIAS}

Alonso, Manuel A. 2001. “Los avances, los retos y la crisis de nuestro campo de conocimiento: reflexiones oblicuas sobre el panorama de la Ciencia Política en Colombia". En La Ciencia Política en la Universidad del Cauca: Ponencias y Discursos de los Actos Conmemorativos, 1996-2001, editado por Andre-Noel Roth Deubel y Lydia Córdoba Hoyos, 55-85. Popayán: Editorial Universidad del Cauca.

Barrero, Fredy y Angel, Sergio. 2014. "Los retos de la Ciencia Política en Colombia". Iberoamericana 14 (56): 191-195

Bejarano, Ana M. y Wills, María E. 2005. "La ciencia política en Colombia: de vocación a disciplina". Revista de Ciencia Política 25 (1): 111-123

Botero, Felipe. (ed.). 2010. En prensa. Elecciones, partidos y Congreso: 40 años de análisis de la democracia en Colombia. Bogotá: Ediciones Uniandes.

Casas, Andrés, et al. 2014. "El síndrome de Zelig revisitado: identidad disciplinar y vida profesional de los egresados de ciencia política en Colombia". Ponencia presentada en III Congreso Colombiano de Ciencia Política (ACCPOL), 27 de Septiembre, Popayán.

Cuéllar, Julián. 2007. "Un diagnóstico a la enseñanza de la Ciencia Política en Colombia". Civilizar 13 (7): 265-295.

Departamento de Gobierno y Ciencias Políticas de la Universidad EAFIT. 2014. “La trayectoria profesional de los politólogos de EAFIT". Trabajo presentado el 19 de noviembre, Medellín.

Duque, Javier. 2013. “Tres momentos de la institucionalización de la enseñanza de la Ciencia Política en Colombia, 1968-2012". En La Ciencia Política en Colombia: ¿una disciplina en institucionalización?, editado por Santiago Leyva, 57-100. Medellín: Colciencias, Asociación Colombiana de Ciencia Política, Centro de Análisis Político - Universidad EAFIT.

Duncan, Gustavo. 2014. Más que plata o plomo. El poder político del narcotráfico en Colombia y México. Bogotá: Penguin Random House.

Fortou, José A. et al. 2013. “El estado de la ciencia política en Colombia: una revisión de la literatura sobre el estado e historia de la disciplina en el país". En La Ciencia Política en Colombia: ¿una disciplina en institucionalización?, editado por Santiago Leyva, 27-56. Medellín: Colciencias, Asociación Colombiana de Ciencia Política, Centro de Análisis Político - Universidad Eafit.

Fortou, José A. y Leyva, Santiago. 2013. “Un análisis bibliométrico de microcurrículos de Ciencia Política en Colombia". En La Ciencia Política en Colombia: ¿una disciplina en institucionalización?, editado por Santiago Leyva, 189-216. Medellín: Colciencias, Centro de Análisis Político - Universidad Eafit.

García, Mauricio et al. 2011. Los Estados de País: Instituciones municipales y realidades locales. Bogotá: Dejusticia.

Giraldo, Jorge (ed.). 2013. Economía criminal y Poder Político. Medellín: Colciencias, Asociación Colombiana de Ciencia Política, Centro de Análisis Político - Universidad Eafit.

Goodin, Robert E. 2010. The Oxford Handbook of Political Science. Oxford: Oxford University Press.

Goodin, Robert E. y Klingemann, Hans-D. 1996. Political science: The discipline. A new Handbook of Political Science. Oxford: Oxford University Press.

González, Fernán. 2014. Poder y Violencia. Bogotá: CINEP-ODECOFI.

Gutiérrez, Francisco. 2014. El orangután con sacoleva. Cien años de democracia y represión en Colombia (19102010). Bogotá: Editorial Debate

Gutiérrez, Francisco. 2007. ¿Lo que le viento se llevó? Los partidos políticos y la democracia en Colombia 19582002. Bogotá: Norma.

Guzmán, Carlos E. 2013. "La Ciencia Política en el Caribe colombiano" En La Ciencia Política en Colombia: ¿una disciplina en institucionalización?, editado por Santiago Leyva, 139-160. Medellín: Colciencias, Asociación Colombiana de Ciencia Política, Centro de Análisis Político - Universidad Eafit.

Isaza, Carolina. 2014. "Disfuncionalidades del servicio civil en Colombia". Reflexión Política 16 (32): 6-19.

King, Gary et al. 1994. Designing Social Inquiry: Scientific Inference in Qualitative Research. New Jersey: Princeton University Press.

Leal, Francisco, 1988. "La profesionalización de los estudios políticos en Colombia". Análisis Político 3 (1): 56-59.

Leal, Francisco. 2011. "Prólogo: Cuatro décadas de Ciencia Política en la Universidad de los Andes". En Partidos y elecciones en Colombia, editado por Felipe Botero, 9-18. Bogotá: Editorial Universidad de los Andes. 
Leiras, Marcelo, et al. 2005. “La Ciencia Política En Argentina: El Camino de la Institucionalización dentro y fuera de las aulas universitarias". Revista De Ciencia Política 25 (1): 76-91.

Leyva, Santiago. 2013. "Introducción". En La Ciencia Política en Colombia: ¿una disciplina en institucionalización?, editado por Santiago Leyva, 11-24. Medellín: Colciencias, Asociación Colombiana de Ciencia Política, Centro de Análisis Político - Universidad Eafit.

Losada, Rodrigo. 2004. "Reflexiones sobre el Estado Actual de la Ciencia Política en Colombia". Papel Político 16: 9-27.

Losada, Rodrigo y Casas, Andrés. 2008. Enfoques para el análisis político. Bogotá: Pontificia Universidad Javeriana.

Mahoney, James. 2007. "Debating the State of Comparative Politics: Views from Qualitative Research". Comparative Political Studies 40 (1): 32-38.

Mahoney, James y Goertz, Gary. 2012. A Tale of Two Cultures: Qualitative and Quantitative Research in the Social Sciences. New Jersey: Princeton University Press

Milanese, Juan P. y Fernández, Juan J. 2013. “El desarrollo de la Ciencia Política en Cali, 1988-2012" En La Ciencia Política en Colombia: ¿una disciplina en institucionalización?, editado por Santiago Leyva, 127-138. Medellín: Colciencias, Asociación Colombiana de Ciencia Política, Centro de Análisis Político - Universidad Eafit.

Munck, Gerardo y Richard Snyder. 2007a. "Debating the Direction of Comparative Politics: an Analysis of Leading Journals". Comparative Political Studies 40 (1): 5-31.

Munck, Gerardo y Richard Snyder. 2007b. "Who Publishes in Comparative Politics? Studying the World from the United States". Political Science and Politics 2 (1): 339-346.

Munck, Gerardo y Richard Snyder. 2007c. Passion, Craft, and Method in Comparative Politics. Baltimore: JHU Press

Muñoz, Patricia. 2013. "Presentación". En La Ciencia Política en Colombia: ¿una disciplina en institucionalización?, editado por Santiago Leyva, 7-10. Medellín: Colciencias, Asociación Colombiana de Ciencia Política, Centro de Análisis Político - Universidad Eafit.

Murillo, Gabriel y Ungar, Elisabeth. 1999. “Evolución y desarrollo de la Ciencia Política colombiana: Un proceso en marcha". Revista de Estudios Sociales 4: 36-53

Pasquino, Gianfranco. 2011. Nuevo curso de Ciencia Política. México: Fondo de Cultura Económica.

Restrepo Parra, Adrián. et al. 2013. “¿De qué Ciencia Política estamos hablando? Las potencialidades de un enfoque integrador". Estudios Políticos 43: 13-38

Rivera, Mauricio y Salazar-Elena, Rodrigo. 2011. "El estado de la ciencia política en México Un retrato empírico". Política y Gobierno 18 (1): 73-108.

Restrepo, Jorge A. et al. 2008. "Ritmos de la producción discursiva en Análisis Político. Un análisis cuantitativo". Análisis Político 62: 81.

Roth, André-Noël. 2002. Políticas públicas: Formulación, Evaluación e Implementación. Bogotá: Ediciones Aurora.

Sánchez, Rubén. 2001. "Educación y Ciencia Política". En La Ciencia Política en la Universidad del Cauca: Ponencias y Discursos de los Actos Conmemorativos, 1996-2001, editado por Andre-Noel Roth Deubel y Lydia Córdoba Hoyos. Popayán: Editorial Universidad del Cauca.

Uribe, Mauricio. 2013. La Nación vetada: Estado, desarrollo y guerra civil en Colombia. Bogotá: Editorial Universidad Externado de Colombia.

Santiago Leyva es Profesor del Departamento de Gobierno y Ciencias Políticas, Universidad EAFIT, Medellín-Colombia. Doctor en Administración Pública, Universidad de Lancaster, Inglaterra. Miembro del Grupo de Investigación Sociedad, Política e Historias conectadas.

E-mail: sleyvabo@eafit.edu.co

María Fernanda Ramírez es Profesora del Departamento de Gobierno y Ciencias Políticas, Universidad EAFIT, Medellín-Colombia. Doctora en Teoría Política, Teoría Democrática y Administración Pública, Universidad Autónoma de Madrid, España. Miembro del Grupo de Investigación Sociedad, Política e Historias conectadas.

E-mail: mframire@eafit.edu.co 